\section{SHARP-TAILED GROUSE DANCING IN JANUARY}

RICHARD PICKERING, 1320 Grandview Street W., Moose Jaw, Saskatchewan. $\mathrm{S} 6 \mathrm{H} 6 \mathrm{H} 8$ and BEN CRUISE, 1204 Hochelaga Street W., Moose Jaw, Saskatchewan. S6H 2J4

On 31 January 1987 at $0845 h$, four Sharp-tailed Grouse were observed roosting in a tree at the northeast corner of the Last Mountain Lake Wildlife Management Unit. We stopped to take some photographs, and when the engine was stopped we could hear more grouse. Several grouse were found dancing on a lek. The mild weather $\left(0^{\circ} \mathrm{C}\right)$ may have contributed to this early occurrence of breeding behavior, and we assumed that the grouse roosting in the tree were females watching the dancing males.

EDITOR'S NOTE: Sharp-tailed Grouse have been observed dancing at all times of the year during suitably warm weather. Although the males are observed displaying it is not known whether the female become receptive and begin to search out the males.

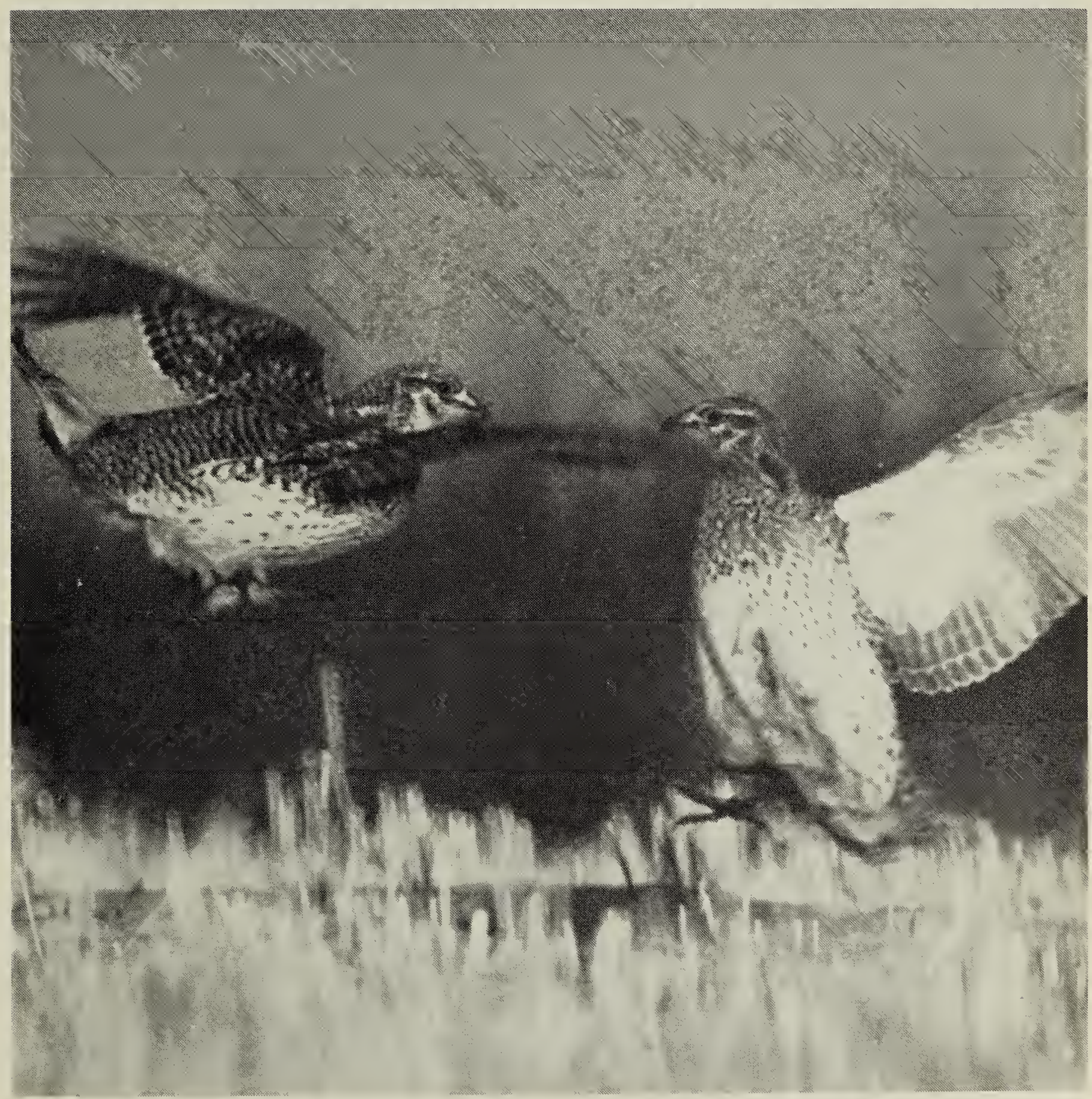




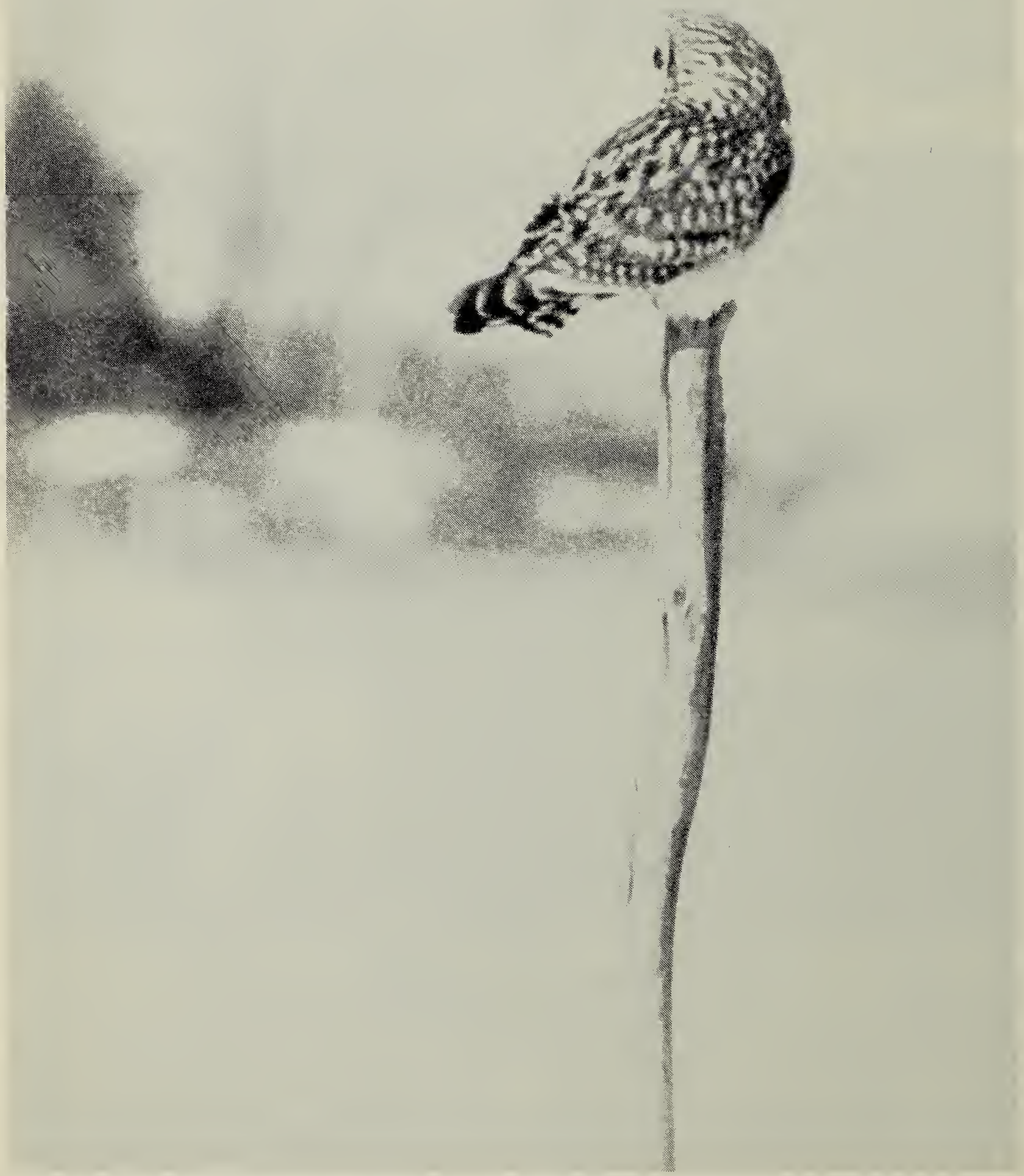

Short-eared Owl near Saskatoon Wayne Shiels/Four Winds Prairie Photography 